\title{
Rapid Determination of Residual Quinolones in Honey Samples by Fast HPLC with an On-Line Sample Pretreatment System
}

\author{
Wei Du², Jian Guo Yao², Yue Qi Li ${ }^{2}$, Yuki Hashi ${ }^{1}$ \\ ${ }^{1}$ Shimadzu Corporation, Kyoto, Japan \\ ${ }^{2}$ Shimadzu International Trading (Shanghai) Co., Limited, Beijing, China \\ E-mail: y-hashi@shimadzu.co.jp \\ Received October 15, 2010; revised February 12, 2011; accepted February 14, 2011
}

\begin{abstract}
A method of on-line pretreatment coupled to HPLC with fluorescence detection was developed and validated for the determination of nine quinolones in honey samples. This method simplified the complicated process of sample pretreatment and reduced sample treatment time. Recovery of the quinolones was between $92 \%$ $101 \%$ for spiked honey samples. The limit of detection was $0.22-3.78 \mathrm{ng} / \mathrm{mL}$ (signal $/$ noise ratio $=3$ ). There was good linear correlation between HPLC peak area and concentration of the quinolones, with a linear range of $1.0-100.0 \mathrm{ng} / \mathrm{mL}$ and correlation coefficients $>0.9997$. The method proposed was validated for detecting quinolones in honey samples.
\end{abstract}

Keywords: Antibiotics, High Performance Liquid Chromatography (HPLC), Honey; On-Line Pretreatment, Quinolones

\section{Introduction}

Nowadays, food safety is one of the biggest social concerns. Therefore, the monitoring of residual pesticides and antibiotics in agricultural products and sea foods must be carried out before these products are released to the market. Recently, high throughput analysis has been considered important in the development of new analytical methods. In particular, the sample pretreatment procedure is a crucial step for high throughput determination [1-11]. There are many kinds of sample preparation procedures in the analytical process [12]. Among several sample preparation techniques, SPE is getting a high priority to be used as a sample pretreatment because of high recovery, less organic solvent usage, short time for sample preparation, easy operation, and automation $[13,14]$. Sample pretreatment must also be optimized with the combination of various techniques, considering the instrumentation to be used and the degree of accuracy and precision required, whether quantitative or qualitative [15].

Quinolones are a group of synthetic antibacterial compounds for the treatment of several diseases. The use of quinolones in animal production is getting more and more, so, their residual presence in food processed from animal product as a raw material can be found. The European Union has defined the maximum residue limits (MRLs) for several of these compounds in the different food matrices of animal origin, but not for honey. Therefore, we have developed an automated on-line sample pretreatment system coupled with high performance liquid chromatography instruments for the rapid determination of quinolones in honey samples, which enabled us not only to minimize the sample preparation time, but also to obtain acceptable analysis precision. According to the guideline of Japan Ministry of Health, Labour and Welfare (MHLW), it may take around 2-3 hours to prepare honey samples. In contrast, the new system reduced the sample preparation time to 10 minutes.

\section{Experimental}

\subsection{Regents and Chemicals}

LC-grade water was obtained by purification of de-ionized water using a Milli-Q system (Waters, Bedford, MA, USA). Acetonitrile (LC grade) was purchased from Fisher (Fair Lawn, NJ, USA). All reagents (analyt- 
ical grade) and the standard quinolones were purchased from Wako (Osaka, Japan).

\subsection{HPLC Systems}

The system used in the present study consisted of three LC-20AD pumps, a DGU-20A3 degassing unit, a SIL20AC auto-sampler, a CTO-20AC column oven including FCV-12AH flow-channel selection valves and an RF-10Axl fluorescence detector with semi-microflow cell (Shimadzu Corporation, Kyoto, Japan). System control and data acquisition were performed using LC-Solution version 1.21 workstation software. A Shim-Pack VP-GODS (4.6 mmI.D. × 10 mmL.; Shimadzu Corporation) guard column and a Shim-Pack XR-ODS (3 mmI.D. $\times 75 \mathrm{mmL}, 2.2 \mu \mathrm{m}$; Shimadzu Corporation) analytical column were used.

\subsection{Sample Preparation}

Honey samples were diluted ten times to $0.1 \mathrm{mg} / \mathrm{mL}$ with sodium dodecylsulfonate (SDS) aqueous solution and then filtered by $0.45 \mu \mathrm{m}$ of membrane filter. $100 \mu \mathrm{L}$ of each sample solution was injected into the system.

\subsection{Chromatographic Conditions}

The flow diagram of this system is shown in Figure 1. $95 \%$ of acetonitrile and $5 \%$ of pure water at $0.1 \mathrm{~mL} / \mathrm{min}$ was used as the enrichment pump solvent, with 1.0 $\mathrm{mmol} / \mathrm{L}$ SDS aqueous solution at $1.9 \mathrm{~mL} / \mathrm{min}$ as the dilution solvent for $2 \mathrm{~min}$ as an enrichment time. Therefore, the sample was diluted 20-fold.

To analyze the target quinolones, a solvent mixture of acetonitrile (25\%) and SDS solution (75\%) which is 1.0 $\mathrm{mmol} / \mathrm{L}$ sodium dodecylsulfonate contained $30 \mathrm{mmol} / \mathrm{L}$ phosphate buffer ( $\mathrm{pH} 2.5$ ), at $1.0 \mathrm{~mL} / \mathrm{min}$ was used as the optimized mobile phase. The column temperature was set at $40^{\circ} \mathrm{C}$. An excitation wavelength of $325 \mathrm{~nm}$ and emission wavelength of $365 \mathrm{~nm}$ were selected for oxolinic acid, nalidixic acid and flumequine, and an excitation wavelength of $295 \mathrm{~nm}$ and emission wavelength of 445 nm were selected for norfloxacin, ciprofloxacin, danofloxacin, enrofloxacin, orbifloxacin and difloxacin.

\section{Results and Discussion}

\subsection{Minimization of the Carry-Over Problem}

When dilution pump was not configured in this system, several carry-over peaks appeared by injection of sample solvent after actual honey sample analysis. The function of washing for sample injector works but was not complete. Increasing organic solvent for sample pump is one of ways to remove carry-over peaks, but it results in poor recovery of quinolones. Therefore, dilution pump was added to this system in order to improve recovery with no carry-over peaks. Comparison of chromatographs with and without dilution pump is shown in Figure 2.

\subsection{Adoption of Fast HPLC Column}

$100 \mu \mathrm{L}$ of nine types of quinolone samples was injected in this on-line sample pretreatment system and the

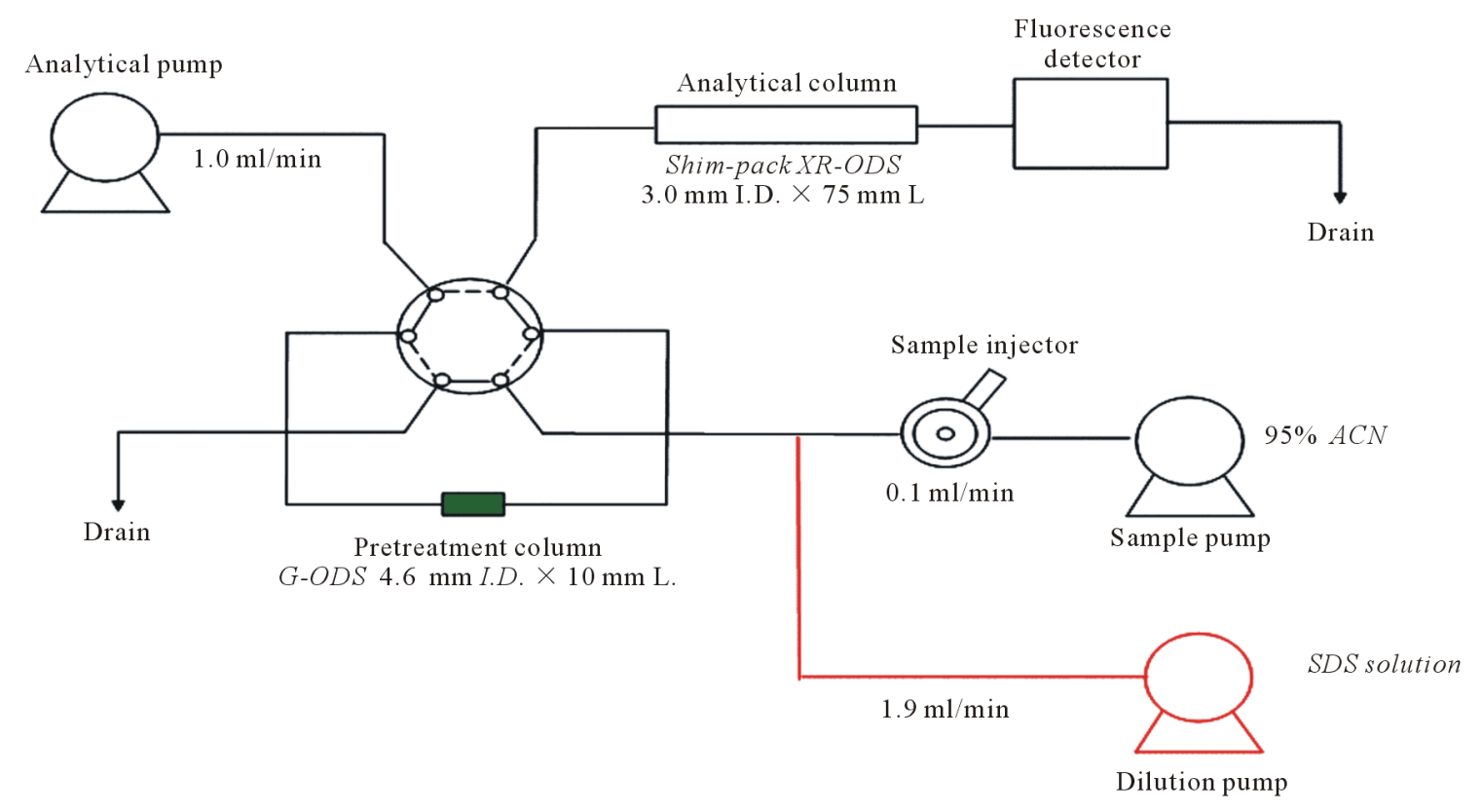

Figure 1. Flow diagram of enrichment and clean-up system. 
chromatograms of standard quinolones are shown in Figure 3. Although $2.2 \mu \mathrm{m}$ packing material was adopted as a fast HPLC column with on-line pretreatment system, nine quinolones could be completely separated within $20 \mathrm{~min}$. In case of using conventional HPLC column (5 $\mu \mathrm{m}$ packing material) more than $70 \mathrm{~min}$ is required for this analysis.

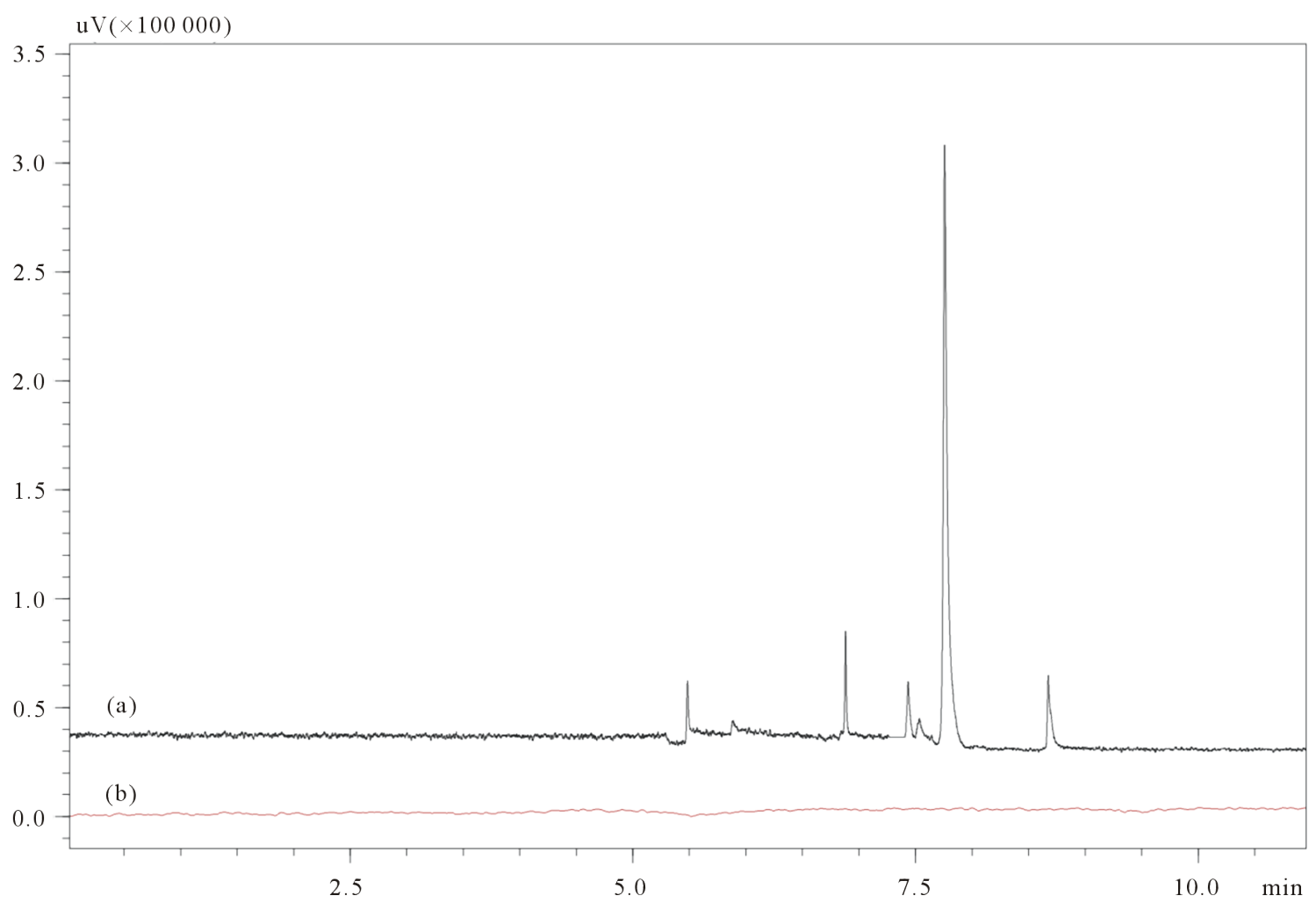

Figure 2. Comparison of chromatographs with / without dilution pump. (a) without using dilution pump; sample pump solvent is SDS solution. (b) with using dilution pump; sample pump solvent is $\mathbf{9 5 \%}$ of acetonitrile and $5 \%$ of SDS solution, and dilution pump solvent is SDS solution.

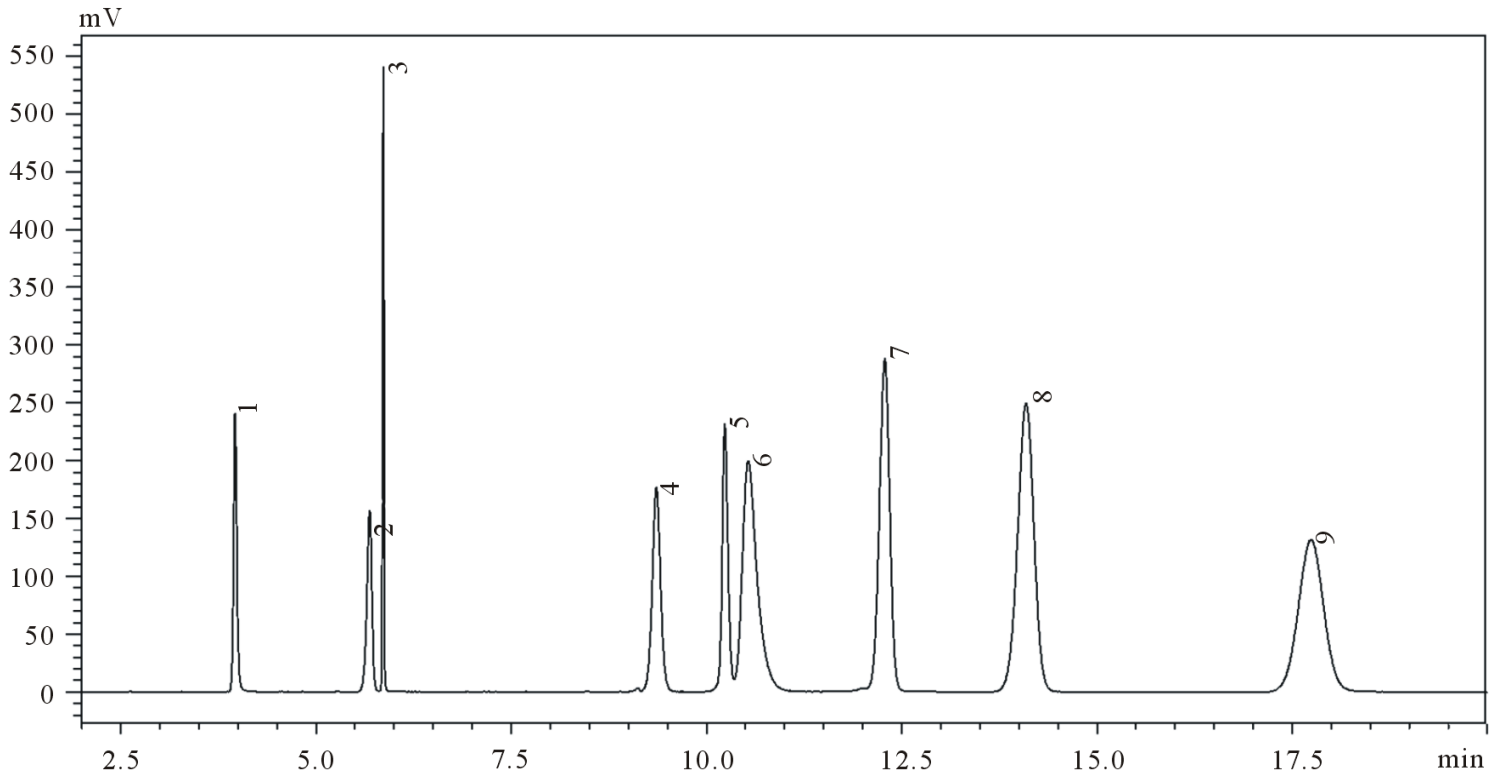

Figure 3. Chromatograms of quinolones. 1 oxolinic acid, 2 nalidixic acid, 3 flumequine, 4 norfloxacin, 5 ciprofloxacin, 6 danofloxacin, 7 enrofloxacin, 8 orbifloxacin, 9 difloxacin. 


\subsection{Analytical Performance}

The linear relationship of the HPLC peak area with the concentration of quinolones in the range $1.0-100.0$ $\mathrm{ng} / \mathrm{mL}$ is shown in Table $\mathbf{1}$.

The sample concentration and the peak area showed an excellent linear relationship. Regression coefficients were all greater than 0.9997 . The limit of detection for the method was determined as 3 times the signal/noise ratio and yielded values of $0.22-3.78 \mathrm{ng} / \mathrm{mL}$. Recoveries of the quinolones were between 92\% - 101\%. The repeatability of the method was determined from five repeated injections of all standard samples (Table 2). The relative standard deviation for the peak areas was less than $0.88 \%(n=5)$.

\subsection{Actual Quinolone Analysis in Honey Samples}

Two brands of honey were diluted ten times with SDS solution and filtered. $100 \mu \mathrm{L}$ of the solutions were injected into the system. The chromatogram and results are shown in Table 3 and Figure 4. As a comparison, Japanese honey association method was also used as a sample pretreatment.

Norfloxacin in sample 2 was detected from two different sample pretreatments with similar concentration values. This indicates on-line sample pretreatment system works as good as conventional sample pretreatment method.

\section{Conclusions}

A method of on-line pretreatment coupled to HPLC with fluorescence detection was developed and validated for the determination of nine quinolones in honey samples. This method simplified the complicated process of sample pretreatment, and reduced sample treatment time. The method was validated in terms of recovery,

Table 1. Linearity, LOD and recovery for the Quinolones (1.0 - 100.0 ng/mL).

\begin{tabular}{ccccc}
\hline Compound & Regression equation & Regression coefficient $\left(\mathrm{r}^{2}\right)$ & LOD (ng/ml) & Recovery (\%) \\
\hline oxolonic acid & $\mathrm{y}=1.408 \mathrm{e}^{-4} \mathrm{x}-0.1116$ & 0.9999 & 0.44 & 94.5 \\
nalidixic acid & $\mathrm{y}=2.754 \mathrm{e}^{-4} \mathrm{x}-0.1689$ & 0.9999 & 3.78 & 98.9 \\
flumequine & $\mathrm{y}=7.833 \mathrm{e}^{-5} \mathrm{x}-0.3249$ & 0.9999 & 0.22 & 101.0 \\
norfloxacin & $\mathrm{y}=7.553 \mathrm{e}^{-5} \mathrm{x}+0.4179$ & 0.9999 & 2.10 & 92.2 \\
ciprofloxacin & $\mathrm{y}=8.249 \mathrm{e}^{-5} \mathrm{x}+0.4014$ & 0.9999 & 0.41 & 95.8 \\
danofloxacin & $\mathrm{y}=9.314 \mathrm{e}^{-6} \mathrm{x}+0.1414$ & 0.9999 & 1.73 & 95.5 \\
enrofloxacin & $\mathrm{y}=3.724 \mathrm{e}^{-5} \mathrm{x}+0.3418$ & 0.9999 & 1.05 & 93.1 \\
orbifloxacin & $\mathrm{y}=2.712 \mathrm{e}^{-5} \mathrm{x}+0.2200$ & 0.9999 & 1.91 & 99.3 \\
diflfloxacin & $\mathrm{y}=6.653 \mathrm{e}^{-5} \mathrm{x}+0.9672$ & 0.9999 & 96.7
\end{tabular}

Table 2. repeatability for the Quinolones $(100 \mathrm{ng} / \mathrm{mL}, n=5)$.

\begin{tabular}{ccc}
\hline Compound & & RSD (\%) \\
\cline { 2 - 3 } & Retention time & 0.254 \\
\hline oxolonic acid & 0.128 & 0.316 \\
nalidixic acid & 0.125 & 0.188 \\
flumequine & 0.132 & 0.665 \\
norfloxacin & 0.083 & 0.293 \\
ciprofloxacin & 0.253 & 0.539 \\
danofloxacin & 0.143 & 0.877 \\
enrofloxacin & 0.094 & 0.465 \\
orbifloxacin & 0.129 & 0.229 \\
diflfloxacin & 0.194 & 0 \\
\hline
\end{tabular}


Table 3. Concentration of quinolones in the two brands of honey.

\begin{tabular}{lll}
\hline & \multicolumn{2}{l}{ Concentration (ng/g) } \\
\cline { 2 - 3 } & Sample 1 & Sample 2 \\
\hline norfloxacin & - & $23.1 / 21.9^{*}$
\end{tabular}

*Guideline of Japan MHLW.

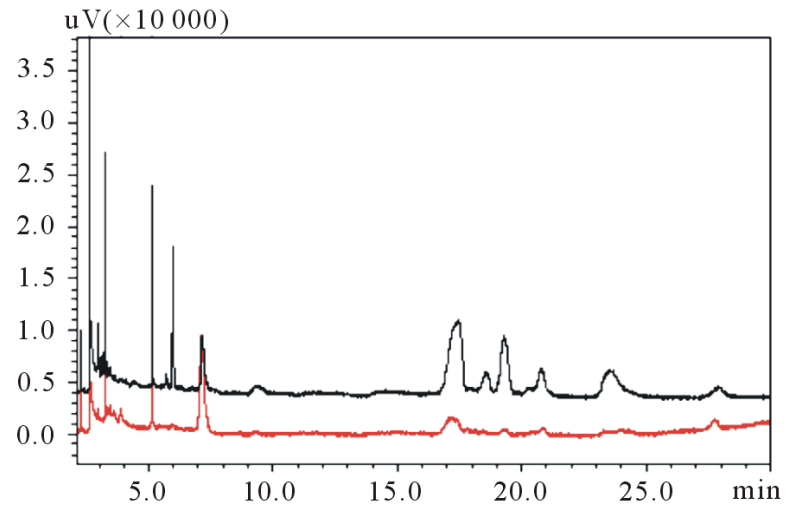

Figure 4. Chromatogram of two brands of honey obtained by on-line sample pretreatment system.

repeatability and linearity and allowed rapid determination of quinolones in honey samples.

\section{Acknowledgements}

The authors wish to thank S. Itoh of Kato Brothers Honey Co., Ltd for the technical support in the experiment.

\section{References}

[1] C. F. Li, J. W. C. Wong, C. W. Huiea and M. M. F. Choia, "On-Line Flow Injection-Cloud Point Preconcentration of Polycyclic Aromatic Hydrocarbons Coupled with HighPerformance Liquid Chromatography," Journal of Chromatography A, Vol. 1214, No. 1-2, December 2008, pp. 11-16. doi:10.1016/j.chroma.2008.10.062

[2] P. Tsytsik, J. Czech and R. Carleer, "Thermal Extraction coupled with Gas Chromatography-Mass Spectrometry as a Tool for Analysing Dioxin Surrogates and Precursors in Fly Ash,” Journal of Chromatogr. A, Vol. 1210, No. 2, November 2008, pp. 212-221. doi:10.1016/j.chroma.2008.09.071

[3] L. W. Lim, Y. K. Okouchi and T. Takeuchi, “On-Line Preconcentration of Trace Carcinogenic Polycyclic Aromatic Hydrocarbons (PAHs) in Microcolumn Liquid Chromatography via Large Volume Injection,” Talanta, Vol. 72, No. 5, July 2007, pp. 1600-1608. doi:10.1016/j.talanta.2007.02.033

[4] A. T. K. Tran, R. V. Hyne and P. Doble, "Determination of Commonly Used Polar Herbicides in Agricultural Drainage Waters in Australia by HPLC," Chemosphere, Vol.
67, No. 5, March 2007, pp. 944-953. doi:10.1016/j.chemosphere.2006.11.002

[5] Y. T. Li, J. E. George, C. L. McCarty and S. C. Wendelken, "Development and Application of a Method for the Analysis of $\mathrm{N}$-Acylhomoserine Lactones by Solid-Phase Extraction and Ultra High Pressure Liquid Chromatography," Journal of Chromatography A, Vol. 1134, No. 1-2, November 2006, pp. 170-176. doi:10.1016/j.chroma.2006.09.047

[6] R. M. Almeida and Y. Mauricio, "Gas Chromatographic-Mass Spectrometric Method for the Determination of the Herbicides Paraquat and Diquat in Plasma and Urine Samples,” Journal of Chromatography B, Vol. 853, No. 1-2, June 2007, pp. 260-264. doi:10.1016/j.jchromb.2007.03.026

[7] M. R. Boleda, M. T. Galceran and F. T. Ventura, “Trace Determination of Cannabinoids and Opiates in Wastewater and Surface Waters by Ultra-Performance Liquid Chromatography-Tandem Mass Spectrometry,” Journal of Chromatography A, Vol. 1175, No. 1, December 2007, pp. 38-48. doi:10.1016/j.chroma.2007.10.029

[8] Y. Song, S. Zhao, P. Tchounwou and Y. L. Min, “A Nanoparticle-Based Solid-Phase Extraction Method for Liquid Chromatography-Electrospray Ionization-Tandem Mass Spectrometric Analysis,” Journal of Chromatography A, Vol. 1166, No. 1-2, September 2007, pp.79-84. doi:10.1016/j.chroma.2007.07.074

[9] W. D. Wang, Y. M. Huang, W. Q. Shu and J. Cao, "Multiwalled Carbon Nanotubes as Adsorbents of Solid-Phase Extraction for Determination of Polycyclic Aromatic Hydrocarbons in Environmental Waters Coupled with HighPerformance Liquid Chromatography," Journal of Chromatography A, Vol. 1173, No. 1-2, November 2007, pp.27-36. doi:10.1016/j.chroma.2007.10.027

[10] J. B. Baugros, B. Giroud, G. Dessalces, M. F. G. Loustalot and C. C. Olive, "Multiresidue Analytical Methods for the Ultra-Trace Quantification of 33 Priority Substances Present in the List of REACH in Real Water Samples," Analytica Chimica Acta, Vol. 607, No. 2, January 2008, pp. 191-203. doi:10.1016/j.aca.2007.11.036

[11] J. J. B. Nevado, C. G. Cabanillas, M. J. V. Llerena and V. R. Robledo, "Sensitive SPE GC-MS-SIM Screening of Endocrine-Disrupting Herbicides and Related Degradation Products in Natural Surface Waters and Robustness Study,” Microchemical Journal, Vol. 87, No. 1, October 2007, pp. 62-71 doi:10.1016/j.microc.2007.05.004

[12] D. M. Pavlovic, S. Babic, A. J. M. Horvat and M. K. Macan, "Sample Preparation in Analysis of Pharmaceuticals,” TrAC Trends in Analytical Chemistry, Vol. 26, No. 11, December 2007, pp. 1062-1075. doi:10.1016/j.trac.2007.09.010

[13] M. C. Hennion, C. C. D. Coumes and V. Pichon, "Trace Analysis of Polar Organic Pollutants in Aqueous Samples: Tools for the Rapid Prediction and Optimisation of the Solid-Phase Extraction Parameters," Journal of Chromatography A, Vol. 823, No. 1-2, October1998, pp. 147- 161. doi:10.1016/S0021-9673(98)00479-8

[14] M. C. Hennion, "Solid-Phase Extraction: Method Devel- 
opment, Sorbents, and Coupling with Liquid Chromatography," Journal of Chromatography A, Vol. 856, No. 1-2, September 1999, pp. 3-54. doi:10.1016/S0021-9673(99)00832-8

[15] K. Ridgway, S. P. D. Lalljie, R. M. Smith, "Sample
Preparation Techniques for the Determination of Trace Residues and Contaminants in Foods," Journal of Chromatography A, Vol. 1153, No. 1-2, June 2007, pp. 36-53. doi:10.1016/j.chroma.2007.01.134 